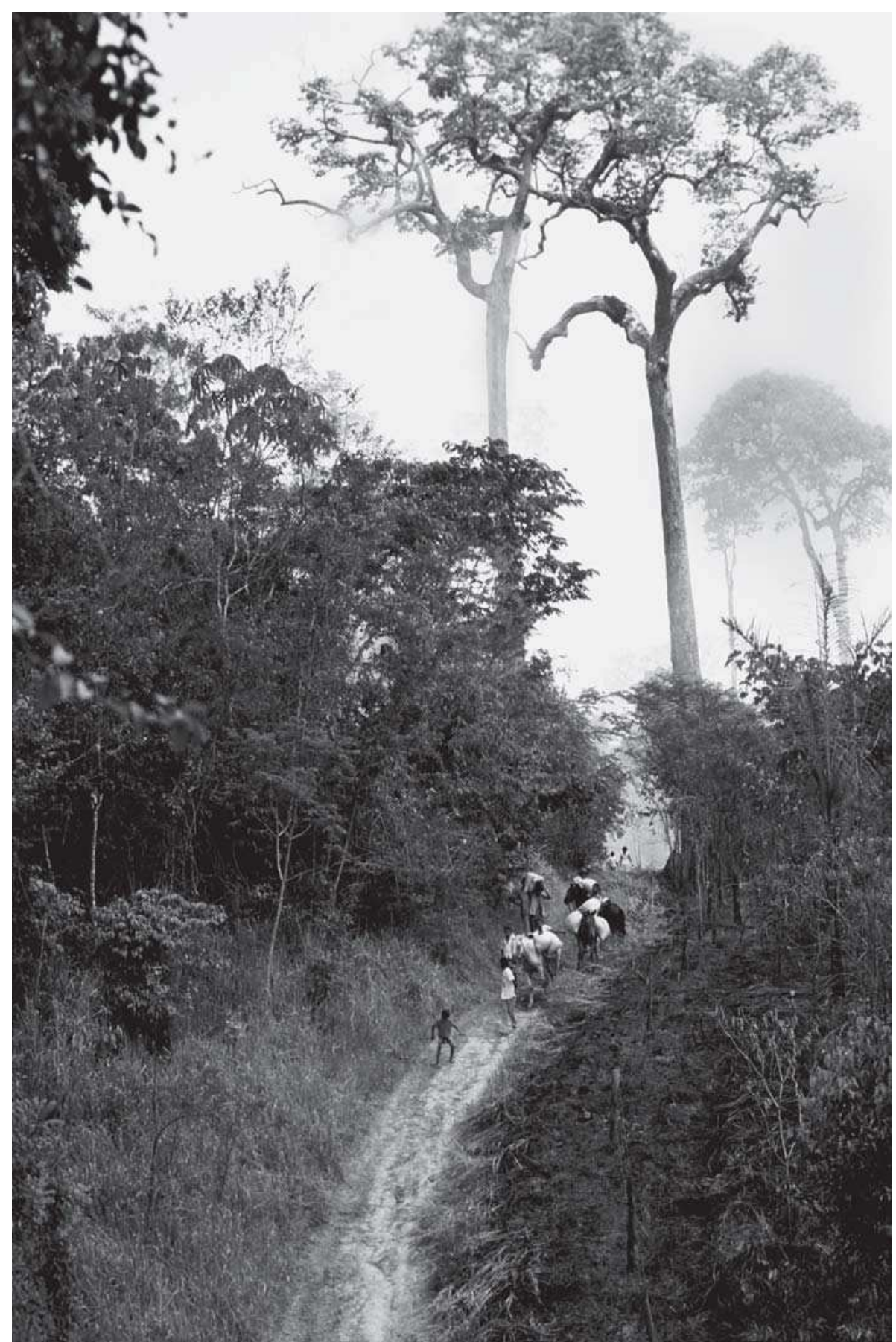

Fotografias: João Roberto Ripper 


\title{
Os indígenas e o direito à cidade: negação e invisibilidade em Manaus (AM)
}

Indians and the right to the city:

denial and invisibility in Manaus (AM)

Norma Maria Bentes de Sousa*

Resumo - O artigo discute as processualidades vividas em Manaus (AM), enfocando as condições de vida e moradia dos indígenas. Busca identificar como eles se inserem no espaço urbano, visando garantir sua reprodução no processo de desigualdade social que marca a cidade capitalista. Os dados utilizados são do Censo Demográfico 2010/ IBGE. Em Manaus, a inserção dos indígenas ocorre nos espaços não valorizados pelo capital, caracterizados pela ausência de condições de habitabilidade, com pouca ou nenhuma oferta de bens e serviços básicos. No que se refere ao trabalho e à renda, predominam, entre os indígenas, as atividades domésticas, de baixa remuneração e formalização. Impõe-se a necessidade de garantia do direito à cidade para eles por meio de políticas públicas que promovam a ruptura tanto de sua invisibilidade, quanto da lógica de mercantilização predominante no espaço urbano.

Palavras-chave: indígenas; urbanização; cidade; Manaus; Amazônia.

\begin{abstract}
This article discusses the processualities lived in Manaus (AM), focusing on the housing and living conditions of indigenous people. It seeks to identify how they fit in the urban space to guarantee their reproduction, in the process of social inequality that marks the capitalist city. Data from the Census 2010/IBGE is used. In Manaus, the inclusion of indigenous people occurs in areas not valued by capitalism, characterized by the absence of housing conditions, with little or no supply of basic goods and services. With regard to employment and income, they remain in domestic activities of low payment and formalization. It's established the need to guarantee the right to the city for the indigenous people, through public policies that promote the breakdown of both its invisibilization and the logic of commodification prevalent in urban space.

Keywords: indigenous people; urbanization; city; Manaus; Amazon.
\end{abstract}

\footnotetext{
*Assistente social (UFPA), mestre em Planejamento Urbano e Regional (IPPUR/UFRJ), doutoranda em Planejamento Urbano e Regional (IPPUR/UFRJ). Analista de informações geográficas e estatísticas do IBGE - Unidade Estadual do Amazonas. Bolsista Fapeam - Programa RH-Doutorado/Fluxo Contínuo. Correspondência: Travessa Barão do Triunfo, 3314 / 104 - Marco, CEP 66093-050, Belém-PA. E-mail: <bentesn@hotmail.com>.
} 


\section{Introdução}

A proposta de uma política desenvolvimentista vigente no país, no período de 1930 a 1960, teve como uma de suas diretrizes a integração da nação, visando superar o "arquipélago econômico" que caracterizava a dinâmica de suas macrorregiões. Inicialmente, o Estado incentivou a formação do mercado interno (integração comercial), num processo hegemonizado pelo Sudeste. Na sequência, promoveu oportunidades econômicas através de incentivos fiscais e financeiros ao capital privado, visando à integração produtiva das regiões economicamente atrasadas (GUIMARÃES NETO, 1997, p. 5).

Concebida de forma contraditória como uma "região problema" e, ao mesmo tempo, como solução para questões regionais/nacionais, a Amazônia foi incoporada às políticas desenvolvimentistas, tendo sido objeto de múltiplas intervenções governamentais (OLIVEIRA, 2008).

Nesse sentido, os processos que envolvem a urbanização e o desenvolvimento regional em curso em Manaus, capital do estado do Amazonas, e que a transformaram no principal centro urbano da Amazônia Ocidental ${ }^{1}$, foram impulsionados especialmente a partir dos anos 1960. Foi neste período que as ações intervencionistas do Estado e do capital (nacional e internacional) aportaram nesse espaço estratégias de controle e produção, tendo em vista a integração econômica da região ao país e a busca por novos espaços para a acumulação capitalista.

Os planos, programas e projetos impostos à região, especialmente pelo governo militar, conceberam a Amazônia (e o estado do Amazonas) como um espaço "vazio", desconsiderando a população que a habitava, especialmente a população indígena. Essa visão estava sintonizada com a política oficial de tutela aos indígenas, por serem considerados incapazes de autodeterminarem-se para promover sua integração à sociedade nacional.

O objetivo deste artigo é refletir sobre a relação entre desenvolvimento regional e urbanização na capital do Amazonas, identificando de que forma a população indígena foi incorporada a esses processos, sua presença e estratégias de sobrevivência para garantir o direito de autoafirmarse e estar na cidade.

\footnotetext{
Para fins de execução do planejamento governamental, a Amazônia foi dividida em duas grandes áreas. Com base no Decreto-lei 291/67, o Governo Federal definiu a Amazônia Ocidental, formada pelos estados do Amazonas e do Acre e pelos territórios de Roraima e Rondônia; já a Amazônia Oriental formou-se pelo estado do Pará e pelo território do Amapá (BRASIL, 1967a).
} 


\section{A Amazônia e o "espaço vazio": a (re)afirmação da invisibilidade indígena}

Anteriormente aos anos de 1930, a economia brasileira assemeIhava-se a um "arquipélago", pois as macrorregiões desenvolviam atividades econômicas pouco articuladas com o centro decisório do país. Nesse sentido, as regiões brasileiras destacavam-se na produção de um produto primário, como a borracha na Amazônia e o açúcar no Nordeste, e exportavamno diretamente para outros países, sem integração com o mercado nacional.

Iniciou-se nesse período, segundo Guimarães Neto (1997, p. 56), a busca por uma articulação regional, tendo em vista a formação do mercado interno. Esse processo foi hegemonizado pela Região Sudeste, especialmente por São Paulo, por possuir estrutura produtiva industrial avançada frente às demais, consolidando desigualdades regionais marcantes até os dias atuais. Nessa fase econômica, segundo Paulani (2013), o Brasil se inseria no contexto mundial do capitalismo como país dependente e produtor de bens primários, contribuindo para o êxito do processo de acumulação nos países do centro, enquanto mantinha a natureza heterônoma de sua economia.

A década de 1960 traz, para a Amazônia, uma nova forma de promover o desenvolvimento e a integração regional à economia do país. A Ditadura Militar, estabelecida no Brasil a partir do ano de 1964, cerceou as liberdades democráticas. No campo da política econômica, foi dada continuidade ao "Desenvolvimentismo Associado", nele incorporando as concepções ideológicas e políticas de "segurança nacional", desenvolvidas pela Escola Superior de Guerra (ESG).

A "Operação Amazônia", anunciada em 1966 pelo General Castelo Branco, constituiu-se numa reformulação da política de desenvolvimento regional a partir da perspectiva dos militares, vinculando-a à doutrina de segurança nacional. Nesse sentido, as propostas de políticas para a região passaram a ter duplo objetivo: promover o desenvolvimento da Amazônia e garantir a segurança do país.

No documento base para a reformulação da política de desenvolvimento e segurança para a Amazônia, o relatório "Operação Amazônia" (BRASIL, 1966), partiu-se de uma concepção da região como espaço vazio, sem presença de população, aberto a possíveis insurreições vindas dos países limítrofes que possuíam atividades de guerrilha.

Nessa perspectiva, ao definir a região como espaço vazio, os militares desconsideraram a existência da população local, como os indígenas, respaldando-se na concepção oficial que via esses povos como desprovidos de condições para autodeterminarem-se, sendo necessária a tutela estatal para que fossem assimilados à sociedade nacional.

O assimilacionismo tinha como diretriz a homogeneização da sociedade brasileira, sendo essa a tônica presente no século XIX (ALMEIDA, 


\section{Revista pll paעtg}

\} OS INDÍGENAS E O DIREITO À CIDADE - SOUSA, N. M. B. \}

2009), defendida por intelectuais e políticos imbuídos do ideal de construção do Estado-nação. Nessa perspectiva, os indígenas eram estimulados a se misturarem para desaparecerem enquanto grupo étnico distinto, e assim fazer parte do povo brasileiro. Ou seja, deveriam invisibilizar-se para serem aceitos pela sociedade nacional. O poder tutelar, na ocasião, era exercido pelo Serviço de Proteção ao Índio (SPI), criado em 1910 como órgão oficial da política indigenista.

Essa concepção oficial sobre a incapacidade dos indígenas de autodeteminarem-se é sintetizada por Oliveira (2013, p. 432) da seguinte forma: "[...] o índio é tido como portador de uma cultura primitiva, incapaz por si só de aprender ou adaptar-se às condições de uma cultura superior." Incapacidade de aprendizagem autônoma e inferioridade de cultura são, portanto, os elementos orientadores da tutela do Estado, direcionando a visão distorcida sobre diversidade cultural dos povos indígenas e, principalmente, sua afirmação como sujeitos no mesmo patamar dos demais grupos sociais existentes no país.

Em 1967, através da Lei no 5.371 de 5/12/1967, foi criada a Fundação Nacional do Índio (Funai) para substituir o SPI (BRASIL, 1967). O novo órgão da política indigenista manteve a mesma diretriz assimilacionista e a visão dos indígenas como seres inferiores².

Por outro lado, imbuídos da ideologia de segurança nacional, os militares temiam a possilibilidade de a região ser porta de entrada para grupos com outras orientações político-ideológicas dos países vizinhos, num contexto de Guerra Fria, que dividia o mundo em dois grandes blocos, o capitalista e o comunista. Essa ideologia estava sintetizada na frase "integrar para não entregar", utilizada pelos militares na definição das ações na região.

Nesse aspecto, inserem-se outros dois elementos para justificar a intervenção do Estado na Amazônia, além da necessidade de integração econômica: o discurso de que a área possuía baixa densidade populacional e o fato de estar sendo ocupada por grupos sociais indígenas desprovidos de condições para defendê-la, o que, por conseguinte, tornava-a vulnerável à expropriação por outros povos, respaldado também, neste último caso, pelas interpretações científicas vigentes. Portanto, era urgente a tarefa de ocupação da fronteira amazônica. Conforme Oliveira (1994, p. 86),

A síntese da 'intervenção' pode ser resumida em tamponar fronteiras, vulneráveis tanto pela sua rarefação demográfica quanto por estarem habitadas por indígenas 'menores de idade', definidos assim pela própria Constituição e pela longa prática da relação entre 'civilizados' e as nações indígenas, prática e teoria às quais não faltava a legitimidade 'científica' de uma antropologia tradicional que

\footnotetext{
${ }^{2}$ Somente a partir da Constituição Federal de 1988 os indígenas são reconhecidos como cidadãos portadores de direitos, extinguindo-se a tutela e respeitando o caráter pluriétnico de suas organizações sociais, costumes, línguas, crenças e tradições, além de reconhecer a posse e usufruto de suas terras tradicionais. (OLIVEIRA, 2008).
} 


\section{ReVistg all paUtg}

\} OS INDÍGENAS E O DIREITO À CIDADE - SOUSA, N. M. B. \}

considerava os índios como faltos de história, portanto sem passado, sem presente e sem futuro (o que relembra a Conquista original).

Quanto às ações governamentais, conforme já referido, os militares mantiveram as diretrizes do desenvolvimentismo, a defesa do intervencionismo estatal, a industrialização e o nacionalismo, embora matizadas com suas próprias orientações fundamentadas na Escola Superior de Guerra. O contexto era de maior abertura ao capital estrangeiro em associação ao capital internacional.

Essa introdução do capital estrangeiro para o financiamento das políticas de desenvolvimento levou à denominação desse tipo de política econômica como "Desenvolvimentismo-Associado", vertente inaugurada por Juscelino Kubitscheck e consolidada pelos governos militares no pós64 (FONSECA et al., 2013, p. 412).Em virtude da urgência requerida para promover o desenvolvimento e o povoamento da região, conforme exigiam a segurança nacional e a integração da Amazônia à economia do país, nesse primeiro momento a industrialização não é referendada como atividade principal a ser desenvolvida. As principais ações visavam à integração física, iniciada em 1960 com a construção da Rodovia Belém-Brasília (BR010), com 1.954 km de extensão, que permitiu ligar a Amazônia à capital federal e daí ao Centro-Sul do país. Por sua vez, para interligar a Amazônia na sua porção ocidental, foi construída a Brasília-Porto Velho-Rio Branco (BR-029), com 3.306 km e inagurada em 1961.

A década de 1970 anuncia, para a Amazônia, sua integração produtiva à nação. O governo militar avança na integração física da Região Norte com a construção da Rodovia Transamazônica. Desta vez, incorporando à construção rodoviária o projeto de ocupação do espaço "vazio" amazônico, através de projeto de colonização, ambos no âmbito do Programa de Integração Nacional (PIN).

No PIN, as principais obras para a integração física da Região foram a Rodovia Cuiabá-Santarém (BR 163), a Rodovia Transamazônica (BR 230) e a Rodovia Perimetral Norte (BR 210). Dentre essas três grandes rodovias, a Transamazônica foi concebida como estratégica por interligar o Norte ao Nordeste, permitindo a vinda do "excedente" populacional flagelado pela seca para a região. Ocuparia-se, assim, o espaço "vazio", segundo os militares, e seriam resolvidas as tensões sociais existentes no Nordeste, onde as secas e a falta de acesso à terra impediam a melhoria das condições de vida de parte significativa da população. A colonização ao longo da Transamazônica foi executada via Programa de Redistribuição de Terras (Proterra).

Contudo, devido à ausência de conhecimento sobre a área, a construção da rodovia e o projeto de colonização resultaram em fracasso. A estrada transformou-se num grande problema, especialmente no período de chuvas, quando ficava intransitável. Foi esta situação, dentre outras, 


\section{Revista pll paעtg}

\} OS INDÍGENAS E O DIREITO À CIDADE - SOUSA, N. M. B. \}

que inviabilizou sua conclusão. Além disso, segundo Castro e Alonso (2006, p. 167), a rodovia "tornou-se um território de conflitos étnicos e de violência". Atravessando áreas indígenas como dos Tenharim, no sul do Amazonas, com os impactos da contrução da Transamazônica a população desse grupo indígena foi reduzida de dez mil para cem pessoas, (PEGGION, 2014), demonstrando a violência e o massacre que essa ação governamental representou.

Planos, programas e projetos foram desenvolvidos na Amazônia no âmbito do II Plano Nacional de Desenvolvimento (PND), como o Programa de Pólos Agropecuários e Agrominerais da Amazônia (Polamazônia), o Complexo Minero-Metalúrgico da Amazônia Oriental e o Programa de Desenvolvimento de Recursos Florestais (BRASIL, 1975-1979, p. 6).

Para utilizar a infraestrutura e os investimentos feitos na região, visavam seu uso produtivo com a exploração dos recursos naturais, especialmente minérios e produção agropecuária. Deriva desse período a exploração da Serra dos Carajás, considerada a maior área de minérios do mundo. Conforme Hall (1989), a possibilidade de uma dívida externa para o Brasil, colocada nos anos 1970, pressionou para que a política pública na Amazônia fosse produtora de divisas ao país.

Pelo lado da Amazônia Ocidental, definiu-se a conclusão da implantação do Distrito Industrial e Agropecuário da Zona Franca de Manaus (ZFM), visando desenvolver industrialização e colocar em execução as atividades agropecuárias (BRASIL, 1975-1979, p. 51).

O modelo desenvolvimentista de forte intervenção estatal na Amazônia (e no país) arrefeceu com a crise nos anos 1980 e pela adoção das políticas neoliberais na década de 1990. Contudo, mesmo com o refluxo da economia nacional e o fechamento e/ou abandono de vários projetos iniciados na década de 1970, os investimentos realizados resultaram no avanço econômico na região (agropecuária, mineração e industrialização). Nesse sentido, depois da integração comercial e física, a Amazônia integrou-se de maneira produtiva, contribuindo para a economia e desenvolvimento do país, ainda que de forma subordinada e prenhe de contradições e conflitos.

Os impactos dessas iniciativas no espaço amazônico, tanto rural quanto urbano, podem ser reconhecidos no crescente êxodo rural que a região passou a experimentar, especialmente a partir da década de 1960. Foram desestruturados os meios e modos de sobrevivência (caça, pesca etc.) das populações tradicionais (ribeirinhos, indígenas), forçando à fuga para a cidade, que se apresentava atrativa e possibilitadora de melhoria das condições de vida.

A partir de 1970 a região já se destacava por seu processo de urbanização. Nesse sentido, a taxa de crescimento geométrica de Manaus é superior à de todas as aglomerações urbanas do país até os dias atuais (DINIZ, 2013, p. 13), exceto na década de 1980, quando ficou atrás da Grande São Luis. Esse assunto será melhor enfocado no próximo item. 


\section{Manaus: espaço de desiguadaldes sociais e de negação do direito à cidade para os indígenas}

O nome Manaus é originado de Manaós, índios guerreiros que viveram nessa área onde hoje se localiza a capital do Estado do Amazonas, no século XVII. Pela localização estratégica, a área foi definida como espaço de localização do Forte de São José do Rio Negro, em 1669, visando à defesa dos território pelos colonizadores portugueses frente a outros povos.

Segundo Melo (2009), a ocupação desse território pelos lusos não foi desprovida de conflitos. Além dos Manaós, havia mais dois povos que habitavam essa área, os Tarumã e os Baré. Manaós e Tarumã resistiram às "alianças" promovidas pela ação colonizadora, especialmente os primeiros, que não aceitavam ser escravizados nem pelos missionários ou pelas forças militares (GOVERNO DO ESTADO DO AMAZONAS, s/d). Ambos os povos foram sumariamente dizimados. Já os Barés tiveram uma postura de maior aceitação das "alianças", resistindo e existindo até os dias atuais.

O registro da origem étnica de Manaus é importante, pois resgata essa vinculação com os povos originários do país, situação que é similar à de muitas cidades brasileiras que surgiram nesse período. De qualquer forma, a análise partirá do século XX para entender o processo de urbanização em curso.

Nesse sentido, situando a dinâmica de Manaus no âmbito das ações dos governos militares e suas políticas desenvolvimentistas, em 1967 a capital do Estado do Amazonas passou a sediar o empreendimento Zona Franca de Manaus (ZFM). Concebida originalmente como porto franco, em 1957, a ZFM foi redefinida para abranger atividades de livre comércio, indústria e agropecuária. Inicialmente, foram dinamizadas as atividades de comércio, com isenção de impostos de importação das mercadorias; posteriormente, iniciou-se a atividade e o predomínio da fase industrial.

A política de industrialização promovida na ZFM diferiu da implementada nas outras áreas da Amazônia, pois não se baseou na exploração de recursos naturais, mas na atividade de transformação, particularmente na montagem final de produtos manufaturados. A partir da concessão de incentivos fiscais, grupos privados nacionais e internacionais foram estimulados a desenvolver suas atividades em Manaus, instalando-se no Polo Industrial de Manaus (PIM), tendo lançada sua pedra fundamental em 1968.

Na segunda fase da ZFM, no período de 1976 a 1990, houve predomínio das atividades industriais. Atualmente, depois de passar por várias prorrogações de seus incentivos fiscais, essa política foi garantida em 2014 por mais 50 anos, a partir de 2023, estendendo seus benefícios até o ano de 2073.

É importante situar que não somente os representantes do capital foram atraídos pelos incentivos governamentais para industrializar a Amazônia Ocidental. Os trabalhadores passaram a deslocar-se para a capital do Amazonas de forma massiva, em busca de melhores condições para ga- 


\section{Revista pll paעtg}

\} OS INDÍGENAS E O DIREITO À CIDADE - SOUSA, N. M. B. \}

rantir sua reprodução. Além da busca por melhores oportunidades de trabalho, Manaus é alvo da migração, principalmente do interior do estado, por possuir melhor infraestrutura em serviços de saúde e educação, contribuindo para o esvaziamento populacional dos demais municípios do Amazonas.

A partir de 1970, a região já se destacava por seu processo de urbanização. Em 1991, a capital do Amazonas foi elevada à categoria de metrópole, processo formalizado no ano de 2007, constituindo-se no município-sede da Região Metropolitana de Manaus (RMM), formada por oito municípios. No ano de 2010, Manaus passou a concentrar mais da metade da população do Estado do Amazonas, aumentando sua importância no âmbito regional. Os dados podem ser conferidos na Tabela 1.

Tabela 1. População do município da capital e seu percentual populacional em relação ao da unidade da federação nos censos demográficos: Amazonas e Manaus, 1960 - 2010

\begin{tabular}{lrrr}
\hline Ano & \multicolumn{1}{l}{ Amazonas } & Manaus & $\begin{array}{c}\text { Percentual da população } \\
\text { da capital em relação ao } \\
\text { da unidade da federação - } \\
\%\end{array}$ \\
\hline 1960 & 721.215 & 175.343 & 24,3 \\
1970 & 960.934 & 314.197 & 32,7 \\
1980 & 1.449 .135 & 642.492 & 44,3 \\
1991 & 2.102 .901 & 1.010 .544 & 48,1 \\
2000 & 2.813 .085 & 1.403 .796 & 49,9 \\
2010 & 3.483 .985 & 1.802 .014 & 51,7 \\
\hline
\end{tabular}

Notas:

1- Para 1960 até 1980: População recenseada; 2- Para 1991 até 2010: População residente; 3- Para 2000: Dados da Sinopse Preliminar; 4- Para 2010: Dados da Sinopse.

Fonte: IBGE, 2011.

É importante destacar que, segundo Sousa (2008), esse processo migratório ocorreu dentro da própria Região Norte. Os dados do censo demográfico de 2010 atestam isso, pois 93,17\% dos residentes em Manaus nasceram na Amazônia, principalmente no próprio estado do Amazonas $(84,69 \%)$. Portanto, a composição da população de Manaus, além da que é natural do próprio município, é oriunda majoritariamente de migração intramunicipal, ou seja, dos municípios do interior do estado. A migração intraestadual, proveniente dos demais estados da Região Norte, é responsável por outro importante fluxo, destacando-se o Pará, com 6,99\%, e o Acre, com $0,76 \%$. Dentre as demais regiões destaca-se o Nordeste, que registra 3,95\% em Manaus; as demais têm pouca representatividade. 
As regiões do Centro-Sul do país e outros países são responsáveis pela migração para Manaus de outro tipo de população, atraída pelos incentivos estatais. Oliveira (1994) denominou esse processo de colonização de interesses. Assim,

grupos empresariais que representam não quantidade, mas uma população selecionada da elite econômica veio instalar-se em Manaus visando usufruir dos benefícios ofertados pelo Estado para dinamizar a economia amazonense, dentro de uma estratégia de inserir a Amazônia no modelo capitalista dominante (SOUSA, 2008, p. 29).

É importante destacar que a urbanização de Manaus atinge quase 100\% dos domicílios desse município. A análise da distribuição interna da população de Manaus, com base no Censo 2010, identifica que 458.378, ou seja, 99,46\% dos domicílios da capital amazonense estão localizados na Zona Urbana, contra 2.466 pessoas, ou 0, 54\%, que se situam na Zona Rural (IBGE, s/d).

$\mathrm{Na}$ atualidade, Manaus também se destaca na produção de indicadores econômicos positivos. Um exemplo disso é o Produto Interno Bruto (PIB) municipal, ostentando, desde 2006 até 2010, a 6 a $^{\mathrm{a}}$ colocação no ranking das capitais brasileiras. Em 2010, Manaus ficou atrás somente

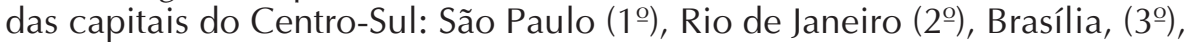
Curitiba (4을 e Belo Horizonte (5응. (IBGE, 2012).

Contudo, ao analisar o acesso à renda produzida nesse município, identifica-se que este não é acessado pela maioria da população. Segundo Sousa (2014, p. 71), enquanto 39,94\% da população possui renda de "até três salários mínimos (SMs)" e 32,53\% declaram-se "sem rendimento", apenas 1,79\% declararam receber "acima de dez SMs". Essa situação reproduz a histórica desigualdade de distribuição daquilo que é produzido coletivamente na sociedade fundada no capital.

Assim, é dentro desse contexto, marcado pelas contradições originadas na forma de produção/apropriação dos bens e serviços na cidade de Manaus, que se encontra a população indígena.

\subsection{Manaus e os indígenas: a negação do direito à cidade}

O Amazonas é a Unidade da Federação com o maior número de população indígena do país, conforme dados do censo do IBGE (s/d), correspondendo a $4,80 \%$ do contigente populacional. No caso de Manaus, 4.040 pessoas se autodeclararam como indígenas ${ }^{3}$, correspondendo a 0 , $22 \%$ dos residentes na capital amazonense.

${ }^{3} \mathrm{O}$ IBGE, ao coletar informações sobre indígenas, capta diferentes categorias sociológicas, nas quais se destacam a de povos indígenas, segundo o preconizado pela convenção 169 da Organização Internacional do Trabalho (OIT), que se diferenciam da coletividade nacional por seus usos, costumes e tradições, e "[...] conjuntos de pessoas que se reconhecem como descendentes de índios (ou índio-descendente), mas que não sabem a que povo ou etnia pertenciam seus ancestrais indígenas." (PEREIRA; SANTOS; AZEVEDO 2005, p. 26). 
Conforme visto inicialmente, Manaus, como muitas cidades brasileiras, originou-se numa área ocupada por indígenas. $\mathrm{Na}$ atualidade, eles se encontram presentes em Manaus, mas não mais na condição de donos do território. Ao contrário, estão nos espaços de negação da cidadania, constituídos por assentamentos precários. Localizam-se nas áreas da periferia da cidade, onde estão ausentes as condições adequadas de habitabilidade e os serviços básicos essenciais, e predomina a falta de planejamento na ocupação e o acesso ilegal à terra. Essas áreas são denominadas de Aglomerados Subnormais (AGSNs) pelo IBGE (2011a).

Nesse sentido, 0,33\% dos moradores dos AGSNs se autoidentificaram como indígenas, proporção superior à do município de Manaus, que é de $0,22 \%$, confirmando ser esse o lugar que predominantemente ocupam na cidade. Os dados podem ser visualizados na Tabela 2.

Essa é a mesma situação constatada por Almeida e Santos (2008), que dizem serem as áreas da periferia da cidade que prevalecem como espaço que os indígenas encontram para morar em Manaus. Conforme Almeida e Santos (2008, p. 36),

O crescimento indígena dentro da cidade que encontra limitações de superfície nas comunidades existentes prevalece nos bairros das periferias. Os Kokama, nos bairros de João Paulo, Cidade de Deus, moram com indígenas da etnia Tikuna, além dos Apurinã que estão principalmente no bairro Valparaíso. Em São João no km 4 da rodovia br-174, Santa Etelvina, Vila Bom Jesus no km 26 e Lagoa Azul II no km 11 da rodovia am-010 moram indígenas do Alto Rio Negro, como Tukano, Desano, Tariano, Tuiuka, Tikuna. No bairro de Lagoa Azul I há também moradores da etnia kokama, além dos bairros João Paulo, Compensa e Santo Agostinho. No bairro de Compensa verifica-se também a presença Kambeba. Os Sateré-Mawé encontram-se principalmente no bairro da Redenção e os Munduruku no bairro de Japiim. $\mathrm{Na}$ estrada do Turismo, km 13 tem indígenas de várias etnias como Miranha, Kokama, Aviana, Sateré-Mawé, Munduruku, Mura e Tikuna.

O baixo acesso ao saneamento adequado \% abastecimento de água canalizado, lixo coletado direta ou indiretamente por serviço de limpeza e esgotamento sanitário desaguando em rede geral ou fossa séptica $\%$, pelos indígenas, confirma a ausência de condições de habitabilidade dos domicílios onde residem. Assim, segundo dados do Censo 2010, são os indígenas que possuem o menor acesso ao abastecimento de água canalizada $(85,33 \%)$ e ao esgotamento sanitário ligado à rede geral ou fossa séptica (57, 46\%) (IBGE, 2010). O único serviço que usufruem em condições iguais aos demais grupos sociais, segundo cor ou raça, é a coleta de lixo feita de forma direta ou indireta por serviço de limpeza, com 98,00\% dos indígenas. Os dados constam na Tabela 3.

Em consonância com o local onde residem, o acesso à educação, para os indígenas, também é bastante precário. Assim, parte majoritária es- 
Tabela 2. População residente em domicílios particulares ocupados, segundo cor ou raça, e o tipo de setor: Manaus (AM), 2010

\begin{tabular}{lccccccc}
\hline \multicolumn{1}{c}{$\begin{array}{c}\text { Município/ } \\
\text { Tipo de setor }\end{array}$} & Total & $\%$ & \multicolumn{5}{c}{ Cor ou raça (\%) } \\
\hline $\begin{array}{l}\text { Manaus } \\
\begin{array}{l}\text { Aglomerados } \\
\text { Subnormais }\end{array}\end{array}$ & 1799213 & 100 & 26,6 & 4,2 & 1,15 & 67,82 & 0,22 \\
\hline
\end{tabular}

Fonte: IBGE, 2011 a.

Tabela 3. População residente, segundo cor ou raça, e o tipo de saneamento (água, lixo, esgotamento sanitário): Manaus - 2010.

\begin{tabular}{cccc}
\hline & \multicolumn{3}{c}{ Saneamento Adequado (\%) } \\
Cor/Raça & $\begin{array}{c}\text { Abastecimento de } \\
\text { Água } \\
\text { Água canalizada }\end{array}$ & $\begin{array}{c}\text { Lixo } \\
\text { Coletado direta/ } \\
\text { indiretamente }\end{array}$ & $\begin{array}{c}\text { Esgotamento Sanitário } \\
\text { Rede Geral/Fossa } \\
\text { séptica }\end{array}$ \\
\hline Indigena & 85,33 & 98,03 & 57,46 \\
Branca & 94,48 & 98,47 & 66,06 \\
Preta & 89,74 & 98,10 & 61,85 \\
Amarela & 92,65 & 97,37 & 65,24 \\
Parda & 91,79 & 97,25 & 60,13 \\
\hline
\end{tabular}

Fonte: IBGE, s/d

tão na condição de "Sem Instrução" ou possuem somente o nível de ensino "Fundamental Incompleto", correspondendo a 62,93\%. O segundo nível de ensino com maior número de pessoas autodeclaradas como indígenas é o "Médio Completo ou Superior Incompleto", com 19,22\%, seguido por "Fundamental Completo e Médio Incompleto", com 9,90\%, e por "Superior Completo", correspondente a 7,95\%. Os dados estão demonstrados no Gráfico 1 . 
Gráfico 1. Indígenas segundo o nível de instrução: Manaus, 2010
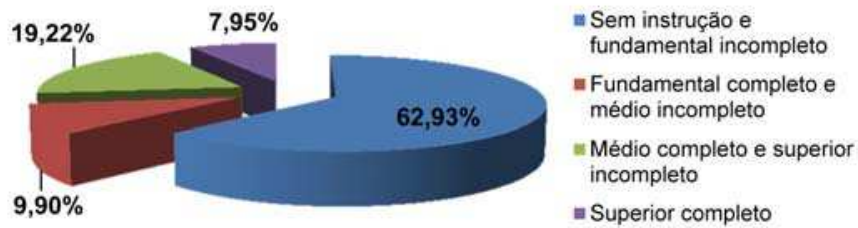

=Superior completo

Fonte: IBGE apun sursa $(\angle \cup, \tau)$.

Outro importante indicador de condições de vida tem a ver com a renda e o acesso ao trabalho e à renda. No primeiro aspecto, a forma de inserção dos indígenas no mercado de trabalho se dá, principalmente, na atividade de serviços domésticos, onde estão presentes $25,00 \%$ dessa população, destoando significativamente dos demais grupos sociais por cor/ raça em Manaus (Gráfico 2). Esse setor de atividade se caracteriza pela precariedade das relações trabalhistas, com baixos salários e alto grau de informalidade, espoliando seus trabalhadores. Conforme Sousa (2014, p. 43),

Historicamente a atividade doméstica tem sido uma profissão de cor e, tradicionalmente da cor preta. Contudo, na capital amazonense, essa atividade adquire matizes regionais, tendo a frente outro grupo social que tende compartilhar a mesma base da pirâmide social no referente ao acesso a cidadania, neste caso, a indígena.

Gráfico 2. População residente, dividida por cor ou raça, segundo o setor de atividade - serviços domésticos: Manaus, 2010

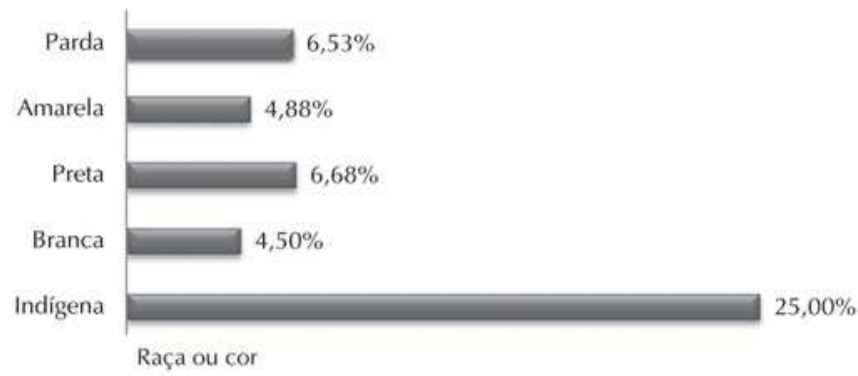

Fonte: IBGE apud Sousa (2014).

$\mathrm{E}$, quanto aos rendimentos, os indígenas dividem com os pardos a situação dos mais baixos salários. Assim, segundo os dados do Censo 2010 , indígenas têm renda média de $R$ \$ 584,73, enquanto pardos têm R \$ 574,84 . Nos demais grupos sociais segundo cor/raça, coube à população 


\section{ReVistg all paUtg}

\} OS INDÍGENAS E O DIREITO À CIDADE - SOUSA, N. M. B. \}

branca ocupar o lugar mais alto da pirâmide, com média de rendimentos de $R \$ 1.164,32$; as de cor amarela e as de cor preta vêm em seguida, com, respectivamente, $\mathrm{R} \$ 787,51$ e $\mathrm{R} \$ 663,45$ (IBGE, s/d). Os dados constam da Tabela 4.

Tabela 4. População residente, segundo cor ou raça, e a média do total de rendimentos brutos, em reais $(R \$)$ - Manaus - 2010.

\begin{tabular}{|c|c|c|}
\hline \multirow{2}{*}{ Cor ou raça } & \multicolumn{2}{|c|}{ Renda Bruta - R\$ } \\
\hline & Média & Pessoas \\
\hline Indigena & 584,73 & 4406 \\
\hline Branca & 1164,32 & 475997 \\
\hline Preta & 663,45 & 75309 \\
\hline Amarela & 787,51 & 21181 \\
\hline Parda & 574,84 & 1225067 \\
\hline Ignorado & $x$ & $\mathrm{x}$ \\
\hline Total & & 1.801 .960 \\
\hline
\end{tabular}

Nota: X - Dados restritos devido ao pequeno número de observações na amostra, comprometendo a precisão da estimativa.

Fonte: IBGE, s/d

Vistos em conjunto, os dados socioeconômicos relativos às características do indígenas demonstram o quanto Manaus, capital amazônica, reproduz o sistema desigual de acesso aos bens e serviços urbanos necessários a uma vida em condições adequadas.

Os indígenas, enquanto grupo étnico diferenciado, estão dentre os demais grupos, segundo cor/raça, em situação bastante adversa. Têm como moradia assentamentos precários, nas periferias, com poucos serviços básicos essenciais. A educação formal é restrita e os postos de trabalho são, principalmente, num segmento bastante precarizado nas relações trabaIhistas e de baixa remuneração, ou seja, os serviços domésticos.

\section{Considerações finais}

Nos mais de quarenta anos em que predomina a política de desenvolvimento regional, denominada Zona Franca de Manaus (ZFM), com foco na industrialização, a capital do Amazonas se metamorfoseou num grande centro urbano, concentrando população e investimentos econômicos ao mesmo tempo em que reproduz as contradições e conflitos inerentes ao modelo pautado na lógica de acumulação capitalista. 


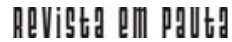

\} OS INDÍGENAS E O DIREITO À CIDADE - SOUSA, N. M. B. \}

Em Manaus, os indígenas, habitantes originários desse território, vivem como se não o fossem. É negado a eles o direito à cidade, seja através do local de moradia, nos aglomerados subnormais, seja por não possuírem acesso à educação. A ocupação ocorre em setores de baixo rendimento salarial e frágil regulação trabalhista, elementos fundamentais para transpor as barreiras impostas pela lógica de mercantilização presente no espaço urbano.

Ainda que de forma não explícita, além da exclusão do direito à cidade, prerrogativa dos processos inerentes à lógica de mercantilização predominante no espaço urbano, identifica-se uma não aceitação e valorização dos grupos indígenas. Portanto, é necessária a elaboração de políticas afirmativas que venham ao encontro de suas demandas específicas e possibilitem a desmercantilização da cidade. 


\section{ReVistg all paUtg}

\} OS INDÍGENAS E O DIREITO À CIDADE - SOUSA, N. M. B. \}

\section{Referências}

ALMEIDA, A.W.B.; SANTOS, G.S. (Org.). Estigmatização e território: mapeamento situacional dos indígenas em Manaus. Manaus: Projeto Nova Cartograûa Social da Amazônia (NCSA-UEA/PPGAS-UFAM/PPGSCA- UFAM). 2008.

ALMEIDA, M.R.C. O lugar dos índios na história entre múltiplos usos do passado: reflexões sobre cultura histórica e cultura política. In: SOIHET, R. et al. (Org.). Mitos, projetos e práticas políticas: memória e historiografia. Rio de Janeiro: Civilização Brasileira. 2009.

BRASIL. Ministério Extraordinário para a Coordenação dos Organismos Regionais (Mecor). Relatório Operação Amazônia. 1966.

. Decreto-lei n. 291 de 28 fev. 1967a.

. Lei n. 5.371 de 5 dez. 1967.

. II Plano Nacional de Desenvolvimento (PND). 1975-1979.

CASTRO, E.; ALONSO, S. Processo de transformação e representações do rural-urbano em Altamira. In: CARDOSO, A.C.D. O rural e o urbano na Amazônia: diferentes perspectivas. Belém: Ed. UFPA. 2006.

DINIZ, C.C. Dinâmica regional e ordenamento do território brasileiro: desafios e oportunidades. Belo Horizonte: UFMG/Cedeplar. 2013.

FONSECA, P.C.D.; CUNHA, A.M.; BICHARA, J.S. O Brasil na Era Lula: retorno ao desenvolvimentismo? Nova Economia. Belo Horizonte, v. 23, n. 2, maio/ago. 2013.

GUIMARÃES NETO, J. Desigualdades e políticas regionais no brasil: caminhos e descaminhos. Revista Planejamento e Políticas Públicas, n. 15, jun. 1997.

GOVERNO DO ESTADO DO AMAZONAS. Biblioteca Virtual do Amazonas. Manaus, s/d. Disponível em: <http://www.bv.am.gov.br/portal/conteu do/municipios/manaus.php>. Acesso em: 12 fev. 2014.

HALL, A.L. O desenvolvimento da Amazônia brasileira. In: HALL, A.L. Amazônia: desenvolvimento para quem? Rio de Janeiro: Jorge Zahar Editor. 1989. IBGE. Sinopse do Censo 2010. Rio de Janeiro, IBGE. 2011.

. Censo demográfico. Aglomerados subnormais: primeiros resultados. Rio de Janeiro, IBGE. 2011a.

. Censo demográfico 2000 e 2010. Banco de dados Sidra. (s/d). Disponível em: <www.ibge.gov.br>. Acesso em: nov./jul. 2011.

. Censo demográfico 2010. Características gerais dos Indígenas. Resultados do Universo. Rio de Janeiro, IBGE. 2012.

IBGE. Estatísticas do Cadastro Central de Empresas (Cempre, 2012. Disponível em: <cidades@.ibge.gov.br>. Acesso em: 15 set. 2014. 
. Produto interno bruto dos municípios 2010. Rio de Janeiro, Contas Nacionais, n. 39. 2012.

MELO, J.G. Identidade Fluidas: ser e perceber-se como Baré (Aruak) na Manaus contemporânea. 2009, 225 f. Tese (Doutorado em Antropologia Social) - Instituto de Ciências Sociais, Universidade de Brasília - UNB, 2009.

OLIVEIRA, F. A reconquista da Amazônia. In: D’INCÃO, M. A.; SILVEIRA, I. M. da (Org.). A Amazônia e a crise da modernização. Belém: Museu Paraense Emílio Goeldi. 1994.

OLIVEIRA, J.A. Manaus: transformações e permanências, do forte à metrópole. In: CASTRO, E. (Org.). Cidades na floresta. São Paulo: Annablume. 2008

OLIVEIRA, J.P. Formas de dominação sobre o indígena na fronteira amazônica: Alto Solimões, de 1650 a 1910. Caderno CRH. Salvador: UFBA, v. 25, n. 64, jan./abr. 2012.

OLIVEIRA, J. P. O paradoxo da tutela e a produção da indianidade: ação indigenista no Alto Solimões (1920-1970). In: FREIRE, C.A.R. Memória do SPI: textos, imagens e documentos sobre o Serviço de Proteção aos Índios (1910-1967). Rio de Janeiro: Museu do Índio/Funai. 2013.

PAULANI, L. Acumulação sistêmica, poupança externa e rentismo: observações sobre o caso brasileiro. Estudos Avançados, São Paulo, v. 27, n. 77. 2013.

PEGGION, E. Indígenas cobram compensação por massacre na abertura da Transamazônica Entrevista concedida à Agência Pública, 15 jan. 2014. Disponível em: <http://ultimosegundo.ig.com.br/brasil/2014-01-15/in digenas-cobram-compensacao-por-massacre-na-abertura-da-transama zonica.html $\geq$. Acesso em: 25 out. 2014.

PEREIRA, N.O.M.; SANTOS, R.V.; AZEVEDO, M.M. Perfil demográfico socioeconômico das pessoas que se autodeclararam 'indígenas' nos censos demográficos de 1991 e 2000. In: PAGLIARO, H.; AZEVEDO, M.; SANTOS, R. (Org.). Demografia dos povos indígenas no Brasil. Rio de Janeiro: Editora Fiocruz, 2005. Disponível em: <http://books.scielo.org>. Acessado em: 20 nov. 2012.

SOUSA, N.M.B. Indicadores sociais no Amazonas: contrastes na urbanização da capital e do interior. Manaus: Muiraquitã. 2008.

. Manaus: realidade e contrastes sociais. Manaus: Valer/Caritas. 2014. Indígenas em Manaus: condições de vida e contrastes na cidade. Manaus: 2014, mimeo.

Recebido em 26 de outubro de 2014 Aprovado para publicação em 25 de novembro de 2014. 